\title{
Nanoparticles for Cell Specific Drug Delivery
}

\section{K. LANGER}

Institut für Pharmazeutische Technologie und Biopharmazie, Westfälische Wilhelms-Universität, Münster, Germany

E-mail: k.langer@uni-muenster.de

Sci Pharm. 2010; 78: 546

doi:10.3797/scipharm.cespt.8.L06

Nanoparticles represent useful drug delivery systems for the specific transport of drugs to target cells and tissues. Over the last 30 years a multitude of different nanoparticle systems based on several starting materials were described. Recently, albumin based nanoparticles were approved by the FDA and EMEA as drug delivery device for tumor therapy. Most often nanoparticles are developed with the aim of selectively transporting a drug to a diseased tissue or organ. To reach this goal, such drug carrier systems may be combined with targeting ligands, which enable a cell-specific accumulation of the nanoparticles.

Within the presentation the development of targeted nanoparticles for tumor therapy will be described. The preparation and characterisation of antibodymodified protein-based nanoparticles will be focused [1]. The ability of the particle systems to specifically accumulate in different tumor cell models by receptor-mediated endocytosis will be presented [2].

The results indicate that protein-based nanoparticles conjugated to an antibody against a specific cellular epitope hold promise as selective drug delivery systems for the treatment of cells and tissues expressing a specific cellular antigen.

[1] Steinhauser I, Spänkuch B, Strebhardt K, Langer K. Trastuzumab-modified nanoparticles: Optimisation of preparation and uptake in cancer cells. Biomaterials. 2006; 27: 4975-4983. doi:10.1016/j.biomaterials.2006.05.016

[2] Spänkuch B, Steinhauser I, Wartlick H, Kurunci-Csacsko, E, Strebhardt K., Langer K. Down-regulation of Plk1 expression by receptor-mediated uptake of antisense oligonucleotide-loaded nanoparticles. Neoplasia. 2008; 10: 223-234. doi:10.1593/neo.07916 